\title{
Improving volcanic ash fragility functions through laboratory studies: example of surface transportation networks
}

\author{
Daniel Mark Blake ${ }^{1 *}$, Natalia Irma Deligne ${ }^{2}$, Thomas McDonald Wilson ${ }^{1}$ and Grant Wilson ${ }^{1,3}$
}

\begin{abstract}
Surface transportation networks are critical infrastructure that are frequently affected by volcanic ash fall. Disruption to surface transportation from volcanic ash is often complex with the severity of impacts influenced by a vast array of parameters including, among others, ash properties such as particle size and deposit thickness, meteorological conditions, pavement characteristics, and mitigation actions. Fragility functions are used in volcanic risk assessments to express the conditional probability that an impact or loss state will be reached or exceeded for a given hazard intensity. Most existing fragility functions for volcanic ash adopt ash thickness as the sole hazard intensity metric that determines thresholds for functional loss. However, the selection of appropriate hazard intensity metrics has been highlighted as a crucial factor for fragility function development and recent empirical evidence suggests that ash thickness is not always the most appropriate metric. We review thresholds of functional loss for existing published surface transportation (i.e. road rail, maritime and airport) fragility functions that use ash thickness. We then refine these existing functions through the application of results from a series of recent laboratory experiments, which investigate the impacts of volcanic ash on surface transportation. We also establish new fragility thresholds and functions, which applies ash-settling rate as a hazard intensity metric. The relative importance of alternative hazard intensity metrics to surface transportation disruption is assessed with a suggested approach to account for these in existing fragility functions. Our work demonstrates the importance of considering ash-settling rate, in addition to ash thickness, as critical hazard intensity metrics for surface transportation, but highlights that other metrics, especially particle size, are also important for transportation. Empirical datasets, obtained from both post-eruption field studies and additional laboratory experimentation, will provide future opportunities to refine fragility functions. Our findings also justify the need for rapid and active monitoring and modelling of various ash characteristics (i.e. not ash thickness alone) during volcanic eruptions, particularly as potential disruption to surface transportation can occur with only $\sim 0.1 \mathrm{~mm}$ of ash accumulation.
\end{abstract}

Keywords: Tephra, Volcano, Road, Rail, Maritime, Airport, Risk, Hazard, Intensity, Critical infrastructure

\section{Introduction}

Surface transportation including road, rail and maritime networks (see Table 1 for terminology) are critical for many social and economic functions. Disruption to surface transportation can affect commuter travel, access for emergency services, distribution and provision of goods and services, other infrastructure (e.g. electricity systems, water and fuel) and the economy. Damage and

\footnotetext{
* Correspondence: daniel.blake@pg.canterbury.ac.nz

'Department of Geological Sciences, University of Canterbury, Private Bag,

Christchurch 4800, New Zealand

Full list of author information is available at the end of the article
}

loss of function to surface transportation networks from historical volcanic eruptions worldwide has been qualitatively and semi-quantitatively recorded for roads and airports (e.g. Blong 1984, Nairn 2002, Barnard 2009, Guffanti et al. 2009, Wilson et al. 2014). Quantitative data sourced from historical eruptions or controlled laboratory experimentation has been lacking, meaning that there have been limited empirical or hybrid datasets to develop robust relationships between hazard intensity and network impact (damage and disruption) (Wilson et al. 2017). 
Table 1 Definitions and context of key terminology used within this paper

\begin{tabular}{|c|c|c|c|}
\hline Term & Definition & Paper specifics & References \\
\hline Airport & $\begin{array}{l}\text { Surface transportation site consisting of airfield } \\
\text { and facilities used to service aircraft. }\end{array}$ & $\begin{array}{l}\text { Surface and near-surface ( }<10 \mathrm{~m} \text { above ground) } \\
\text { environmental conditions at airfields are } \\
\text { considered when referring to airports. }\end{array}$ & \\
\hline Exposure & $\begin{array}{l}\text { People, property, systems, or other elements present } \\
\text { in hazard zones that are thereby subject to potential } \\
\text { losses. }\end{array}$ & & UNISDR 2009, Craig et al. 2016b \\
\hline Fragility function & $\begin{array}{l}\text { Probabilistic vulnerability models that describe the } \\
\text { probability that a damage or functional state will be } \\
\text { reached or exceeded for a given hazard intensity. }\end{array}$ & $\begin{array}{l}\text { Only fragility functions for volcanic ash are } \\
\text { discussed in detail. }\end{array}$ & $\begin{array}{l}\text { Singhal and Kiremidjian 1996, } \\
\text { Choi et al. 2004, Rossetto et al. } \\
\text { 2013, Tarbotton et al. } 2015\end{array}$ \\
\hline Hazard & $\begin{array}{l}\text { A phenomenon that may cause loss of life, injury or } \\
\text { other health impacts, property damage, loss of } \\
\text { livelihoods and services, social and economic } \\
\text { disruption, or environmental damage. }\end{array}$ & $\begin{array}{l}\text { Hazard is referred to in the context of a dangerous } \\
\text { phenomenon from volcanoes (i.e. volcanic tephra, } \\
\text { pyroclastic density currents, lava flows, lahars). }\end{array}$ & UNISDR 2009 \\
\hline $\begin{array}{l}\text { Hazard Intensity } \\
\text { Metric (HIM) }\end{array}$ & $\begin{array}{l}\text { A measure used to describe the intensity of a } \\
\text { volcanic hazard at a particular site, which is the } \\
\text { independent variable of vulnerability and fragility } \\
\text { functions. }\end{array}$ & $\begin{array}{l}\text { Ash thickness is often used as the HIM for volcanic } \\
\text { ash fragility functions. Alternative HIMs are } \\
\text { explored here including ash-settling rate and } \\
\text { particle size. }\end{array}$ & Wilson 2015, Wilson et al. 2017 \\
\hline Impact & $\begin{array}{l}\text { The effect a hazardous event has on an exposed } \\
\text { system. Defined as a function of the hazard, and } \\
\text { the vulnerability and exposure of a system } \\
\left(I=H^{*} V^{*} E\right) \text {. }\end{array}$ & $\begin{array}{l}\text { Multiple impact types are inferred when discussing } \\
\text { impact. }\end{array}$ & $\begin{array}{l}\text { Jenkins et al. 2014b, Craig et al. } \\
\text { 2016b }\end{array}$ \\
\hline Impact State (IS) & $\begin{array}{l}\text { States of damage or disruption defined by qualitative } \\
\text { impact descriptions. }\end{array}$ & $\begin{array}{l}\text { These are numbered numerically with } 0 \text { being "no } \\
\text { damage or disruption", and increasing numbers } \\
\text { referring to an increasing level of damage or } \\
\text { disruption. }\end{array}$ & Blong 2003, Wilson et al. 2017 \\
\hline Impact type & $\begin{array}{l}\text { An individual feature of an infrastructure system that } \\
\text { can be affected by the function of hazard, } \\
\text { vulnerability and exposure. }\end{array}$ & $\begin{array}{l}\text { Surface transportation impact types include skid } \\
\text { resistance reduction, visibility impairment, road } \\
\text { marking coverage and engine air inlet filter } \\
\text { blockage. }\end{array}$ & \\
\hline Maritime & Surface transportation connected with the sea. & $\begin{array}{l}\text { Covers trade shipping, recreational boating and } \\
\text { ferry services. }\end{array}$ & \\
\hline Mitigation & $\begin{array}{l}\text { The lessening or limitation of the adverse impacts of } \\
\text { hazards and related disasters. }\end{array}$ & & UNISDR 2009 \\
\hline Rail & $\begin{array}{l}\text { Surface transportation on wheeled vehicles running } \\
\text { on rails. }\end{array}$ & $\begin{array}{l}\text { Covers electric and diesel modes on conventional } \\
\text { tracks. }\end{array}$ & \\
\hline Risk & $\begin{array}{l}\text { The combination of the probability of an event and } \\
\text { its negative consequences. }\end{array}$ & A volcanic hazard is implied to be the "event". & UNISDR 2009 \\
\hline Road & $\begin{array}{l}\text { Surface transportation on dedicated sealed or } \\
\text { unsealed routes. }\end{array}$ & $\begin{array}{l}\text { We generally refer to paved surfaces, particularly } \\
\text { asphalt concrete. }\end{array}$ & \\
\hline Skid resistance & $\begin{array}{l}\text { The force developed when a tyre that is prevented } \\
\text { from rotating slides along apavement surface. }\end{array}$ & $\begin{array}{l}\text { (Often referred to as traction in post-eruption } \\
\text { literature.) }\end{array}$ & $\begin{array}{l}\text { Highway research board 1972, } \\
\text { Blake et al. } 2017 \text { a }\end{array}$ \\
\hline $\begin{array}{l}\text { Surface } \\
\text { transportation }\end{array}$ & $\begin{array}{l}\text { Transportation types on land or water used to } \\
\text { convey passengers and/or goods. }\end{array}$ & $\begin{array}{l}\text { Road, rail and maritime transport are covered, as } \\
\text { well as transport that occurs on the ground at } \\
\text { airports. }\end{array}$ & \\
\hline Visual range & $\begin{array}{l}\text { The longest distance that a large, black object can } \\
\text { be seen against the sky at the horizon with the } \\
\text { unaided eye. }\end{array}$ & Used as a measure of visibility. & $\begin{array}{l}\text { Hyslop 2009, Binkowski et al. } \\
\text { 2002, Blake } 2016\end{array}$ \\
\hline Vulnerability & $\begin{array}{l}\text { The characteristics and circumstances of a } \\
\text { community, system or asset that make it susceptible } \\
\text { to the damaging effects of a hazard. }\end{array}$ & $\begin{array}{l}\text { Largely transportation systems or assets are } \\
\text { referred to. }\end{array}$ & UNISDR 2009 \\
\hline $\begin{array}{l}\text { Vulnerability } \\
\text { function }\end{array}$ & $\begin{array}{l}\text { A correlation of hazard intensity to a component's } \\
\text { damage or function loss as a value relative to total } \\
\text { impact or as an economic cost. }\end{array}$ & $\begin{array}{l}\text { We generally refer to fragility functions instead, } \\
\text { which incorporate probability. }\end{array}$ & Wilson 2015 \\
\hline
\end{tabular}

Figure 1 summarises recorded impacts for road, rail and airports, caused by various volcanic hazards with a focus on tephra, following historical eruptions since 1980. Impacts to transportation networks can be complex, particularly when exposed to multiple volcanic hazards during eruptions causing a range of impact states.
Volcanic hazards such as pyroclastic density currents (PDCs) and lava flows (shown in the top sections of the charts in Fig. 1) are geographically well constrained. Volcanic ash (i.e. the component of tephra with particle size $<2 \mathrm{~mm}$ ) however, is often widespread (Blong 1984) and generally has far-reaching and complex interactions with 


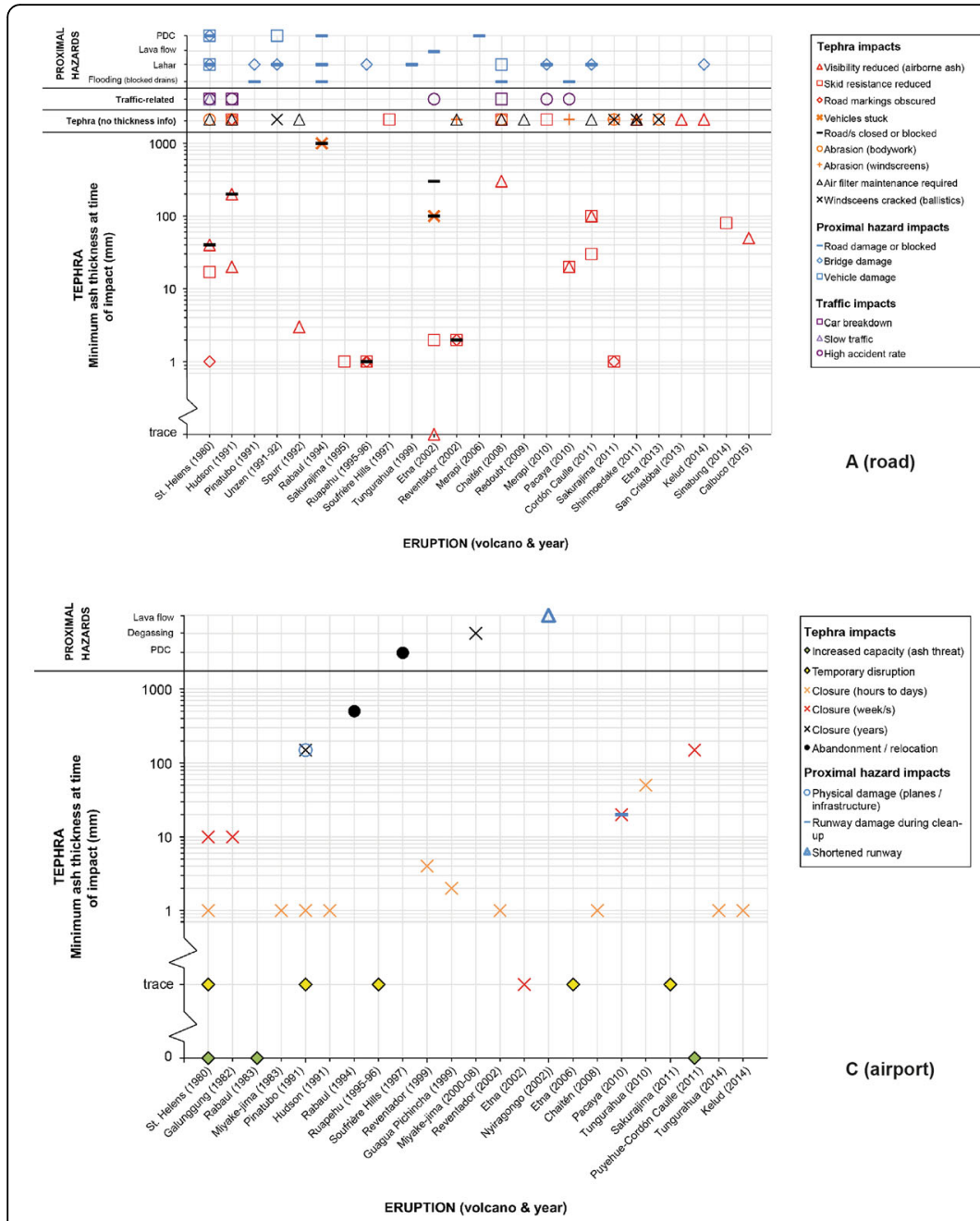

Fig. 1 Post-1980 reports of (a) road, (b) rail and (c) airport impacts following volcanic eruptions worldwide. There are few recorded impacts to transportation from tephra before 1980. Note that the only known reported impacts to maritime transportation since 1980 are from pumice rafts causing abrasion to vessels and obstruction to navigation. These are not shown graphically as they cannot be associated with thickness measurements

surface transportation. Studies since the 1980 Mount St Helens eruption (e.g. Blong 1984, Johnston 1997, Guffanti et al. 2009, Horwell et al. 2010, Wilson et al. 2011, Dunn 2012, Wardman et al. 2012, Wilson et al. 2012, Stewart et al. 2013, Wilson et al. 2014, Blake et al. 2016, 2017a) demonstrate that volcanic ash frequently reduces skid resistance and covers markings on paved surfaces. Reduced visibility caused by airborne ash and the abrasion or cracking of vehicle windscreens are also common, and engine failure may result if vehicle air intake filters are not adequately maintained. All of these impacts can affect transportation functionality, whether it is by reduced vehicle volumes and speed, an increase in accident rates and congestion, or network closures. As such, we focus on the impacts associated with volcanic ash in this paper.

Globally there is limited quantitative data for the impact of ash on surface transportation networks.
Similarly, experimental data is sparse due to the complexities of replicating infrastructural components and volcanic ash properties in laboratories (Jenkins et al. 2014a, Wilson et al. 2014). Where quantitative data exist, impacts on transportation, as well as other critical infrastructure, have generally been related to the thicknesses of ash on the ground. For example, Wilson et al. 2017 use the ash thickness variable (defined as a Hazard Intensity Metric (HIM); Table 1) to produce a series of volcanic ash fragility functions for different infrastructure types. Although adopting ash thickness as a HIM has distinct advantages, particularly in that it is a frequently modelled and often relatively readily measured variable following eruptions, it is not always appropriate to consider this metric alone. Characteristics such as ash particle size, ash type, the quantity of soluble components, wetness and airborne concentration or ashsettling rate may have large effects on overall impact 
intensity and subsequent loss of functionality in some cases. Recent work by Blake (2016), Blake et al. (2016 and 2017a) has focused on targeted experiments investigating common surface transportation impact types for volcanic ash under controlled laboratory conditions through a series of targeted experiments. New quantitative data available from these studies enables analysis of HIM importance and appropriateness, the refinement of thresholds for functional loss (termed Impact State (IS)), and opportunities to improve fragility and vulnerability functions. Such approaches, whereby the vulnerability of infrastructure is assessed using laboratory studies to supplement field-based empirical observations, has been proven in other disciplines including earthquake engineering and for structural loading in tsunami (e.g. Rossetto et al. 2013, Nanayakkara and Dias 2016).

In this paper, we summarise existing IS thresholds for surface transportation from previous, largely qualitative, post-eruption literature, and using ash thickness on the ground as the HIM. Next we adopt the empirical results from Blake (2016), and Blake et al.'s (2016 and 2017a) (see Additional file 1 for key findings summary) suite of targeted laboratory experiments to refine these established thresholds for ash thickness, and to develop new IS options for visibility impairment based on ash-settling rate as the HIM. The importance of additional HIMs (such as ash particle size and colour) as measures of functional loss for specific impact types is investigated through relative comparisons to one another. This allows us to propose a credible strategy to enhance fragility functions for surface transportation networks, by means of incorporating related uncertainty. We only consider discrete and direct ash fall events and not effects that may occur from remobilised ash. Our focus is on road disruption as most garnered data is directly related to road infrastructure. However, disruption to airports and rail and maritime transportation are also discussed, particularly as recent empirical studies of visibility reduction apply to all surface transportation modes.

\section{Background: Quantitative volcanic impact assessments}

Risk assessments may incorporate vulnerability functions to describe the likelihood that an asset will sustain varying degrees of loss over a range of hazard intensities (Rossetto et al. 2013). The 'loss' may be expressed as economic cost, damage (e.g. physical damage of a sealed road surface from ballistics) and/or functionality (e.g. reduced speeds on roads from volcanic ash). However, vulnerability functions are less common in volcanic risk assessments than they are in risk assessments for many other disciplines such as seismic engineering due to the variety of volcanic hazards and associated complexities (Jenkins et al. 2014a).
Qualitative data obtained following eruptions is often considered sufficient to establish and communicate information relating to expected impacts during future events. For example, exclusion zones may be implemented in the immediate vicinity of the vent due to qualitative knowledge gained from past eruptions about the high likelihood of severe damage from proximal hazards such as pyroclastic density currents (PDCs) and lahars, and advice can be issued to avoid travel in relatively short-lived and localised ashfall events until ash has been cleared. Residents often heed such advice due to health concerns (Stewart et al. 2013) and to avoid potential damage to their vehicles (e.g. Blake et al. 2015). However, the volcanic ash hazard can have complex impacts on infrastructure networks causing widespread disruption (Johnston and Daly 1997), potentially affecting thousands of kilometres of surface transportation routes. Loss of functionality can also be prolonged due to ongoing volcanic activity and the remobilisation, resuspension and secondary deposition of ash (sometimes for months to years after an eruption has ceased) by wind, fluvial processes, and/or anthropogenic disturbance. As such, it is beneficial to establish thresholds from semi-quantitative and/or quantitative data (e.g. ash thickness measurements) to indicate when specific impact types (e.g. road marking coverage or visibility impairment), and of what severity, occur. These impact thresholds can in turn inform damage ratios, which express the economic cost required to restore infrastructure (i.e. absolute damage) by indicating the damaged proportion of the infrastructure (i.e. relative loss) (Reese and Ramsay 2010, Tarbotton et al. 2015). Impact thresholds and damage ratios can be adopted by emergency management officials and in transportation maintenance guidelines such as for informing when to commence road sweeping or implement road closures following volcanic ashfall (Hayes et al. 2015). Sometimes however, a more gradational approach to assess the vulnerability of infrastructure to volcanic ash is required and fragility functions can be used in such situations.

Fragility functions are probabilistic vulnerability models that describe the probability that a damage or functional state will be reached or exceeded for a given hazard intensity (Singhal and Kiremidjian 1996, Choi et al. 2004, Rossetto et al. 2013, Tarbotton et al. 2015). They allow the quantification of risk and provide a basis for cost-benefit analysis of mitigation strategies (Jenkins et al. 2014a, Wilson et al. 2014). Data used to create fragility functions can be derived from a variety of sources and is generally classified into four types: 1) empirical data from field and/or laboratory observations, 2) analytical data from numerical modelling, 3) data from expert opinions / judgement, 4) hybrid data from a combination of these approaches (Porter et al. 2012, Wilson et 
al. 2017). Variables can take on either discrete values or a continuous range of values, and as such fragility functions can comprise a number of forms (Porter et al. 2007, Wilson et al. 2017). The reader is referred to Wilson et al. (2017) for more detailed discussion on impact data types and fitting of volcanic fragility functions. To date, most volcanic fragility functions have focused on damage, particularly the physical damage to buildings and roofs. However, loss of infrastructure functionality may be as, if not more, important than damage in some cases. The loss of infrastructure functionality can have potentially large implications for governments and local authorities (e.g. deciding whether to shut down parts of a network) and cause substantial, sometimes unexpected, effects on end-users of critical infrastructure such as drivers and residents through a reduced 'level of service'. It is important to note that there are often many impact types, along with factors such as infrastructure characteristics and decision-making by authorities, which influence whether networks remain open. For example, in New Zealand a main state highway was closed following $<3 \mathrm{~mm}$ of ash accumulation from the 2012 Tongariro eruption (Jolly et al. 2014, Leonard et al. 2014), but in Argentina after the 2011 Cordón Caulle eruption, many key roads remained open despite receiving up to $50 \mathrm{~mm}$ of ash (Craig et al. 2016a). Such differences are likely due to duration of disruption, threat of future ashfall, criticality of the road, previous experiences with volcanic ash and different tolerance levels in different regions (Craig et al. 2016a).

It is difficult to incorporate all factors which contribute to surface transportation closure (Table 2) into volcanic fragility functions. However, these variations in damage and disruption can be accounted for by introducing estimates of uncertainty within fragility functions. Uncertainties include aleatory uncertainties such as natural variations between volcanic eruption hazard severity and resulting infrastructure response, and epistemic uncertainties such as those associated with limited data or choosing appropriate HIMs and ISs (Rossetto et al. 2014, Wilson et al. 2017). These uncertainties are outlined more fully by Wilson et al. (2017). Sometimes, HIMs cannot be measured in the field in real time (Jenkins et al. 2013, Wilson et al. 2017); for example, it may be dangerous to measure ash characteristics due to the ash or other volcanic hazards potentially impacting health. Laboratory experimentation can be used to reduce epistemic uncertainty through the provision of larger impact data sets. Additionally, the controlled nature of laboratory experimentation means that particular conditions can be assessed, and uncertainty can often be reduced in this respect as well. However, the introduction of new data that differs from previous data may reflect either aleatory or epistemic uncertainty. As was conducted by
Wilson et al. (2017), where possible, we account for uncertainties by calculating the probability that the surface transportation mode could be in each IS at each HIM value. Binning the HIM values and adopting the median HIMs on each chart accounts for the variation in values (Wilson et al. 2017). It is important that uncertainties are subsequently transferred across to plans and strategies that utilise fragility functions, ideally using probabilistic techniques to ensure that different outcomes are considered (Jenkins et al. 2014a). However, as new qualitative field data and quantitative data from further laboratory experiments becomes available, existing datasets can be reviewed and fragility functions adjusted accordingly, thus reducing overall uncertainty.

Selection of appropriate HIMs and establishment of representative IS thresholds are crucial to produce robust fragility functions (Rossetto et al. 2013). Wilson et al. (2014) and Wilson et al. (2017) highlight that fragility functions in volcanology are poorly developed compared to those from other natural hazard disciplines. They also outline that the range of intrinsic volcanic hazard properties, such as the particle size of ash, can cause different impacts, leading to difficulties in deriving functions. Additionally, much of the data that has informed volcanic fragility functions is qualitative or semi-quantitative with limited quantitative empirical, analytical or theoretical data from field studies or laboratory experiments.

To date, the most common HIM for volcanic ash fragility functions to assess surface transportation disruption is the thickness of ash on the ground (Wilson et al. 2014). This is largely due to its extensive use in existing impact datasets and applicability to hazard model outputs at the time. Previous IS thresholds that have been defined using thickness as the HIM (Wilson et al. 2017) are shown in our results (section 4.1) for comparative purposes. Of particular note is that $\mathrm{IS}_{1}$ (reduced visibility, loss of traction, covering of road markings and/or road closures) was previously identified as occurring with thicknesses of $\sim 1 \mathrm{~mm}$ or more, due to reduced traction (technically known as skid resistance) and impaired visibility disrupting most transportation types. Impacts to maritime transportation have not been considered in detail in relation to thickness, as most ash types (with the exception on pumiceous material, which can form pumice rafts) do not accumulate, or are readily dispersed, on water and are thus difficult to monitor. The majority of data used to inform previous ISs was from qualitative post-eruption impact assessments and media reports. Observations from Barnard (2009), who conducted a number of semi-quantitative field experiments on Mt. Etna, Italy, also informed ISs for road transportation where thicknesses exceed $50 \mathrm{~mm}$.

Blake (2016), and Blake et al. (2016 and 2017a) conducted targeted experiments under controlled laboratory 


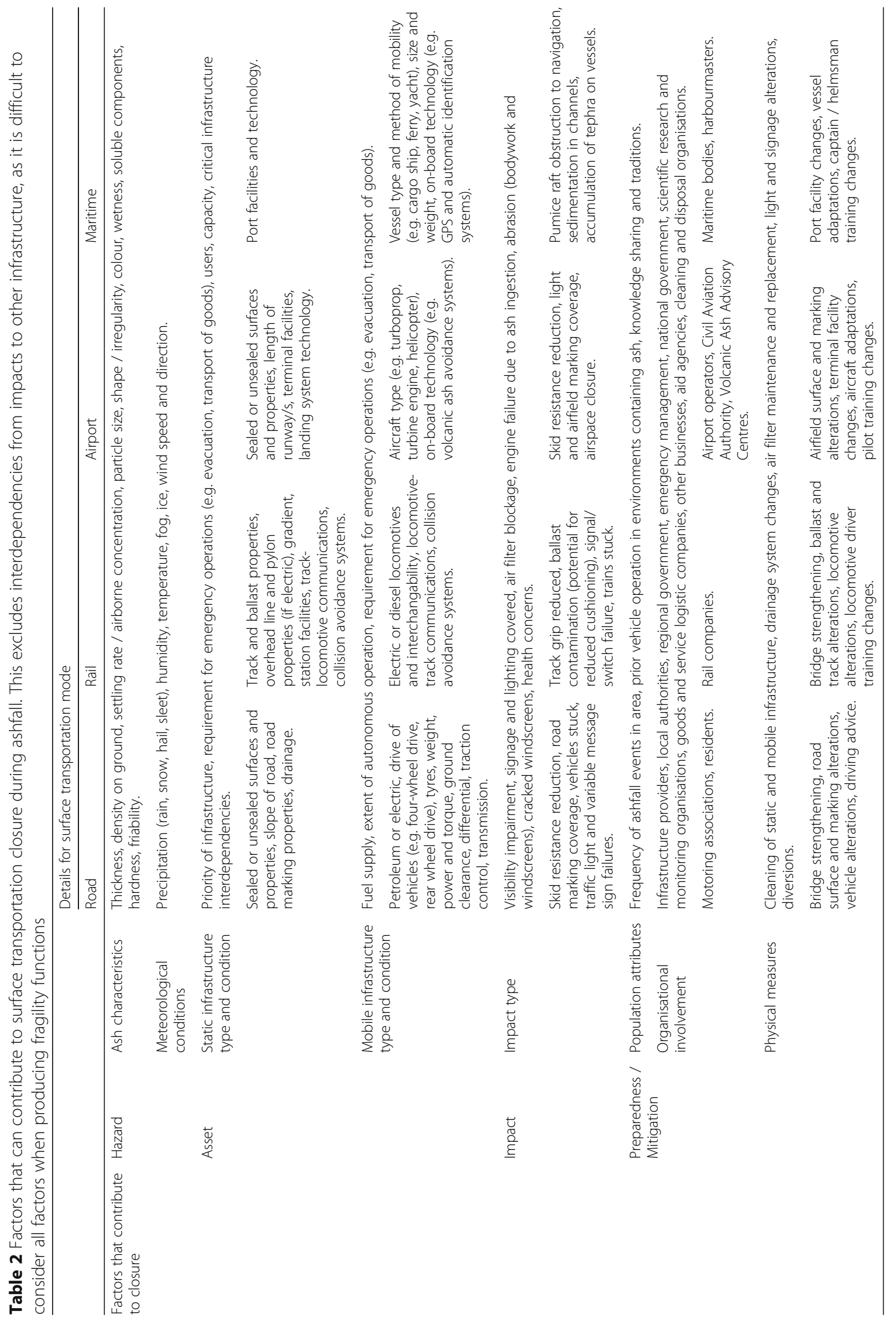


conditions to investigate the most frequent surface transportation impact types identified from posteruption assessments: skid resistance reduction, visibility impairment and road marking coverage (see Additional file 1 for key findings summary). The studies assessed the effect of key HIMs (Table 3) on functionality and we refer the reader to each of the corresponding papers for detailed information on the methodologies adopted for the experiments including different approaches used to measure HIMs.

The studies by Blake (2016), Blake et al. (2016) and 2017a) suggest that ash thickness and ash-settling rate are the most critical HIMs for the assessment of surface transportation functionality during initial volcanic ashfall events, particularly as they are two of the most readily measured variables in the field. There would rarely be impacts to transportation when there is no ground accumulation of ash and no suspended ash in the atmosphere, which further emphasises the importance of these two HIMs. However, recent laboratory work has also revealed that alternative HIMs to ash thickness and settling rate (Table 3) should not be disregarded.

\section{Methodology}

Figure 2 summarises previous and current developments to volcanic ash fragility functions for surface transportation. Most steps in the diagram indicate anticipated improvements to data accuracy. However, as fragility functions are developed, requirements for more impact data are often introduced to test and improve new findings and reduce uncertainty.

\section{Impact state thresholds}

Using the key findings of the skid resistance and road marking coverage laboratory studies, we refine the IS thresholds for surface transportation established by Wilson et al. (2017) which adopt ash thickness as the HIM (Fig. 2). New thresholds are applied directly from laboratory study analysis results but some require rounding to the nearest order of magnitude to account for uncertainties such as those associated with the variation in results between individual tests and lack of extensive datasets in some cases. This is achieved using the authors' expert judgement, particularly through application of existing knowledge of surface transportation impacts by volcanic ash gained from field and laboratory observations. We remove previously suggested correlations between visibility and ash thickness because, as stated by Blake (2016), it is "illogical to associate an atmospheric-related impact to a ground-based measurement", especially as we do not consider effects from remobilised ash in this paper. Laboratory work using ash thickness as the core HIM considered paved surfaces on roads and at airports. Railway tracks were not considered in detail, partly because there has been only one recorded instance of track-wheel adhesion loss following ashfall (Fig. 1b) and the effects were complicated by snowfall at the time. As such, we do not provide any refinements for rail transportation ISs in relation to ash thickness and the previously established thresholds for rail transportation are therefore unchanged by our study. For maritime transportation, a challenge for fragility function development is that due to ash dispersing in water, impact mechanisms from tephra cannot easily be linked to deposition thickness as they can for road, rail and airports. However, as with other forms of transportation, and as occurs in dense fog, it is likely that navigation by sea can be disrupted or even temporarily halted by visibility impairment during ashfall. Therefore, maritime transportation impacts are segregated from the ash thickness HIM and assessed solely in relation to visibility impairment.

As ash deposit thickness has a debatable impact on visibility impairment, and due to recent developments in both field monitoring equipment, and ash dispersion and fallout models which provide settling-rate outputs (Blake 2016), we consider ash-settling rate as an alternative HIM (Fig. 2) and propose new IS thresholds. Our

Table 3 Summary of hazard intensity metrics considered during experimental work

\begin{tabular}{|c|c|c|c|}
\hline Hazard intensity metric & Skid resistance reduction $^{a}$ & Road marking coverage ${ }^{b}$ & Visibility impairment $^{\mathrm{C}}$ \\
\hline $\begin{array}{l}\text { Thickness }(\mathrm{mm}) \text { - related to area density / } \\
\text { loading }(\mathrm{kg} / \mathrm{m} 2) \text { in some cases }\end{array}$ & $\checkmark$ & $\checkmark$ & \\
\hline Ash-settling rate $\left(\mathrm{g} \mathrm{m}^{-2} \mathrm{~h}^{-1}\right)$ & & & $\checkmark$ \\
\hline Particle size $(\mu \mathrm{m})$ & $\checkmark$ & $\checkmark$ & $\checkmark$ \\
\hline Colour & & $\checkmark$ & $\checkmark$ \\
\hline Wetness & $\checkmark$ & & \\
\hline Soluble content & $\checkmark$ & & \\
\hline Hardness (proxy: ash type) & $\checkmark$ & $\checkmark$ & $\checkmark$ \\
\hline Shape (proxy: ash generation method) & $\checkmark$ & $\checkmark$ & $\checkmark$ \\
\hline
\end{tabular}

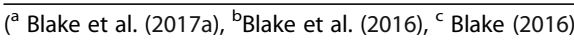




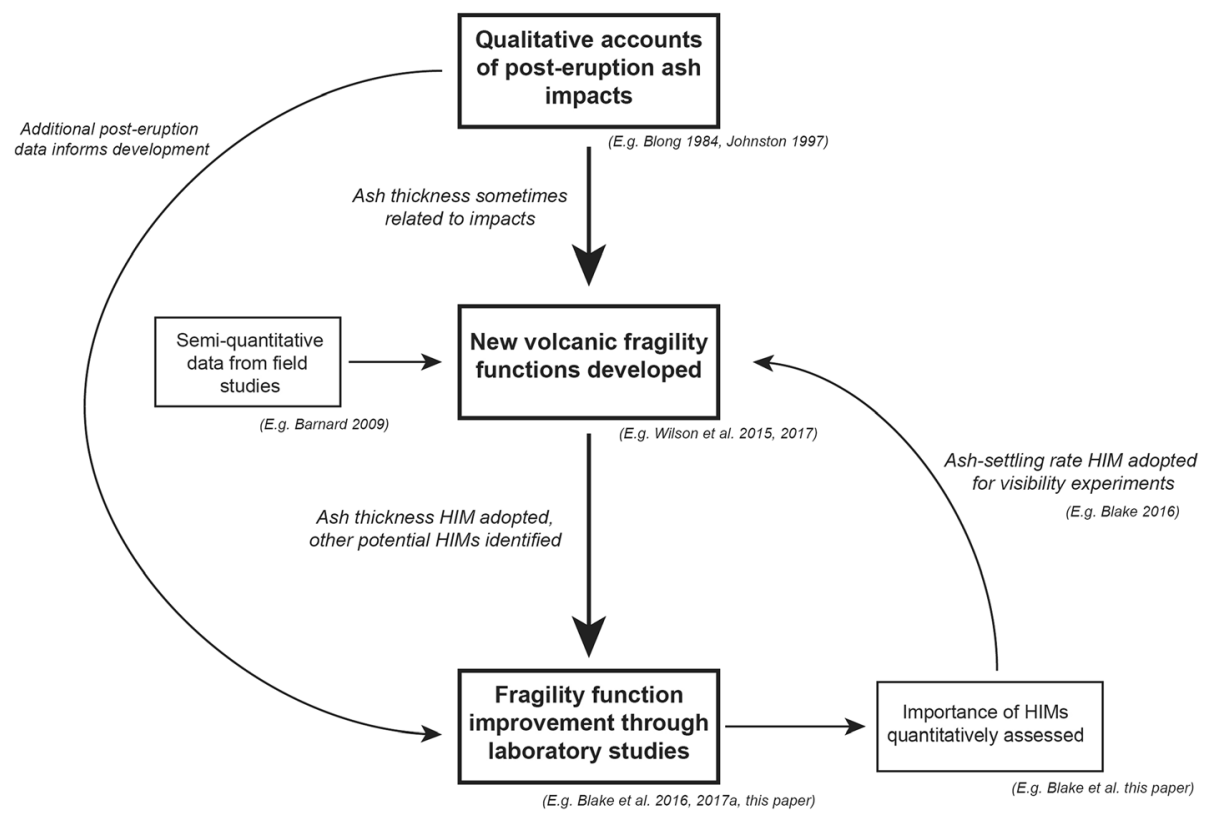

Fig. 2 Previous and current developments to volcanic ash fragility functions for surface transportation

settling rate IS thresholds are developed using a hybrid approach. They are informed by (a) direct empirical laboratory results, adjusted using expert judgement and rounding, (b) literature for shipping in Auckland's Waitemata Harbour (e.g. Harbourmaster and Maritime New Zealand information for maritime impacts (Auckland Council 2014, MNZ 2015)) and Auckland Airport and CAA guidelines for airport impacts (Auckland Airport 2008, CAA 2008), and (c) expert consultation with critical infrastructure managers (Deligne et al. 2015, Blake et al. 2017b, Deligne et al. 2017). We establish IS thresholds for all modes of surface transportation related to visibility impairment. This is achieved by means of comparison with operational guideline information and impact states expected for corresponding visual ranges in foggy conditions, the data sources of which are discussed in Blake (2016):

- IS thresholds for roads are largely based on comparisons with empirical studies involving driver simulations in fog.

- Comparisons with operational procedures for fog in Auckland are used to establish thresholds for airports and maritime transportation, and thus these thresholds should be treated as more area-dependent than for road.

- IS thresholds for rail are the most subjective of the four transportation modes: we implement higher threshold values than for road due to the often automated controls for the spacing of locomotives along the network and additional technological safety systems which visibility impairment does not affect.

\section{Hazard intensity metric analysis}

We conduct a comparative analysis of HIMs other than ash thickness by assessing their relative importance to surface transportation disruption. Without extensive datasets for all HIMs, this is achieved by applying simple rank values to each HIM for the core HIMs of ash settling rate and at different ash thicknesses. HIMs are ordered by relative importance to one another and given a rank value of between 1 and 6 . Although somewhat subjective, the lower the rank value applied, the greater the influence of that HIM on surface transportation disruption. HIMs of similar importance are given the same rank value.

\section{Fragility function development}

We use procedures described by Wilson et al. (2017) for volcanic fragility function development, the basic methodological principles of which are summarised as follows:

- Assign each data point a HIM value and IS value;

- Order data set by increasing HIM value;

- Group into HIM bins, such that each bin has approximately the same number of data points;

- Calculate probability of being greater than, or equal to, each IS of interest;

- Obtain discrete HIM values by taking the median of each HIM bin. 
- Apply functions as linear segments defined by the available data points after the HIM binning process (as described by Wilson et al. 2017).

New road and airport fragility functions for ash thickness are established through modification of those proposed by Wilson et al. (2017). All points representing median thickness within the HIM bins obtained from post-eruption data are retained as the number of posteruption records remains unchanged. New points are added to the chart to appropriately display the new findings from IS threshold adjustment following laboratory work, with a focus on improving functions for relatively thin deposits (the focus of laboratory work). More substantial updates are made to airport fragility functions as we also incorporated the duration of airport closure. However, we stress that some points have been corrected using best judgement in order to fit with guidelines outlined by Wilson et al. (2017).

The IS thresholds for ash-settling rate are used to establish separate fragility functions for road, rail and maritime transportation, and at airports. Without reliable field data it is difficult to follow Wilson et al.'s (2017) methodology for fragility function production, especially to accurately calculate probabilities of ashsettling rate values equalling or exceeding each IS. However, we produce functions using empirical laboratory studies and comparisons to research for fog, to indicate expected impact on visibility and vehicles at nearground level. This is achieved through adopting the basic principles and rules outlined by Wilson et al. (2017). As we cannot group data into HIM bins and obtain discrete HIM values, specific ash-settling rates are chosen based on key changes in impact states instead. We use best judgement to assign probabilities and these are open to revision in future.

\section{Limitations of methodology}

Besides the general limitations outlined by Wilson et al. (2017) for fragility function production, our methodology for fragility function improvement through empirically informed data contains several additional limitations which may also introduce uncertainty:

- The laboratory experiments used to inform fragility functions were based on the assessment of key impact types previously identified from post-eruption observations. However, observations of volcanic ash impacts to transportation are relatively limited (at least compared to impacts from other hazards such as earthquake damage to buildings) with an apparent increase in frequency of events after 1980. We suggest that this increase is due to heightened awareness and land-monitoring of volcanic hazards following the 1980 Mount St Helens eruption, and recent increases in the number of motor vehicles and general population growth and infrastructure development in volcanically active areas worldwide (TRB 1996).

Additionally, there is a higher frequency of impacts recorded for roads than for other modes of surface transportation, likely due to more road networks in the areas affected by volcanic activity. Therefore, the relevance of further impact types may be underestimated by our study, and future observations and additional laboratory testing will verify the extent of this.

- The empirical datasets we use are constrained by the equipment and set-ups that were adopted in the laboratory studies. For example, the skid resistance testing used a Pendulum Skid Resistance Tester, which was restricted to investigating small $(<10 \mathrm{~mm})$ ash thicknesses (Blake et al. 2017a). Furthermore, it was unfeasible to investigate all possible ash characteristics (e.g. every soluble component option, all moisture regimes) during laboratory testing, so our results are limited to those characteristics that we did investigate.

- Laboratory experiments are generally time and resource intensive. As the experiments by Blake (2016), and Blake et al. (2016 and 2017a) were the first to be developed and conducted to specifically assess ash impacts on individual transportation components, the datasets are currently relatively small. The repetition of laboratory experiments will help to reduce uncertainty in the future but our results are limited to those characteristics investigated to date.

\section{Results and discussion}

\section{Ash thickness fragility function improvements}

Figure 3 shows IS thresholds for surface transportation, which were defined using ash deposit thickness as the HIM. It includes thresholds for rail that were unmodified from Wilson et al. 2017, and original (grey) and newly revised (red) thresholds for roads and airports; the revised thresholds were informed by key findings from recent laboratory experiments that can be directly related to ash accumulation (i.e. skid resistance reduction and road marking coverage (Blake et al. 2016, 2017a), in addition to new post-eruption data where available. Figure 3 illustrates that some disruption to roads and airports can occur with an ash thickness of $\sim 0.1 \mathrm{~mm}$, an order of magnitude less than previously suggested by most anecdotal data. Figure 3 also suggests that larger thicknesses of ash may not always result in greater disruption. For example, an ash thickness of $\sim 10 \mathrm{~mm}$ on roads could potentially lead to less disruption than a thickness of $\sim 5 \mathrm{~mm}$ as skid resistance reduction is more likely at $5 \mathrm{~mm}$. Although the 


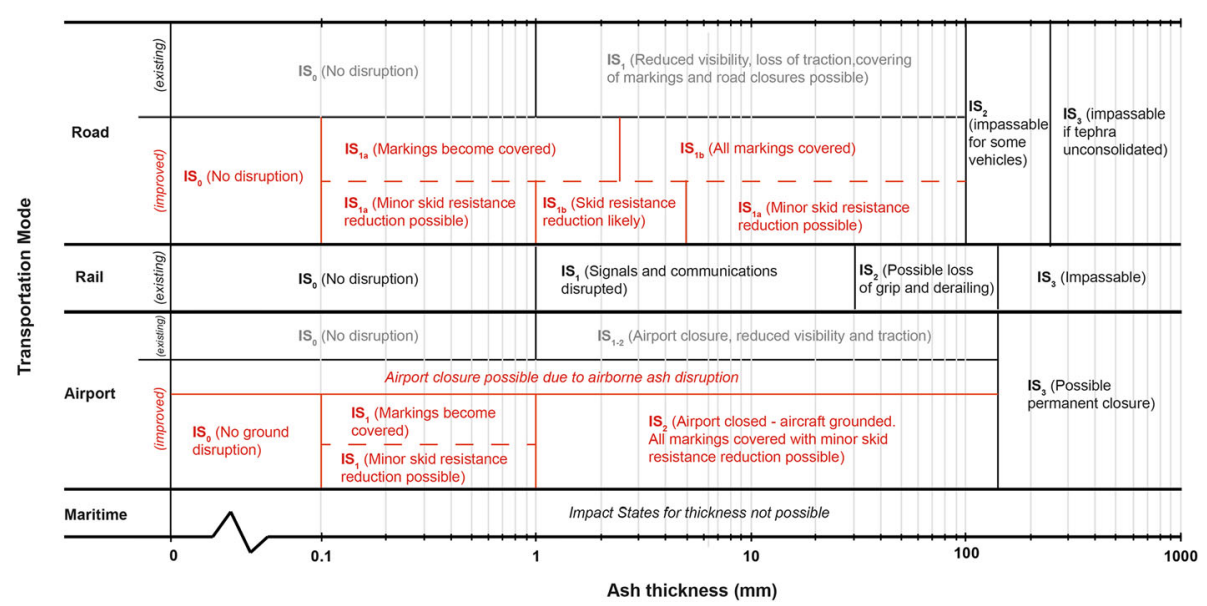

Fig. 3 Impact states for expected ground-related disruption to transportation as a function of ash thickness. The existing impact states (shown in black) were derived from qualitative post-eruption impact assessments and limited semi-quantitative field studies (adapted from Wilson et al. 2017). Impact states that were improved in this study are shown in red

impacts of reduced visibility (accounted for separately) may mask such effects overall, we suggest particularly elevated disruption to road transportation from ash thicknesses between $\sim 2.5$ and $5.0 \mathrm{~mm}$. At this range, all road markings are covered and especially reduced skid resistance occurs. Although limited, the posteruption data available (Blake 2016, Blake et al. 2016 and 2017a) indicate that fewer impacts are identified when ash is 5-20 mm thick, supporting the hypothesis of elevated disruption regions on the thickness scale. Fluctuating intensities of road transportation disruption with thickness have not been identified in the past, highlighting the importance of laboratory testing and the complexities that can be involved in determining accurate IS thresholds.

Figure 4 shows corresponding fragility functions for roads, updated from Wilson et al. 2017. Two new points (at 0.1 and $5.0 \mathrm{~mm}$ ash thickness) have been added to appropriately account for new findings from laboratory work for $\mathrm{IS}_{1}$ (i.e. disruption in the form of skid resistance reduction (Blake et al. 2017a) and road marking coverage (Blake et al. 2016)). The decrease in function observed for $\mathrm{IS}_{1}$ when ash thickness exceeds $5.0 \mathrm{~mm}$ is due to the potential increase in skid resistance; it is largely informed by recent laboratory findings (which do
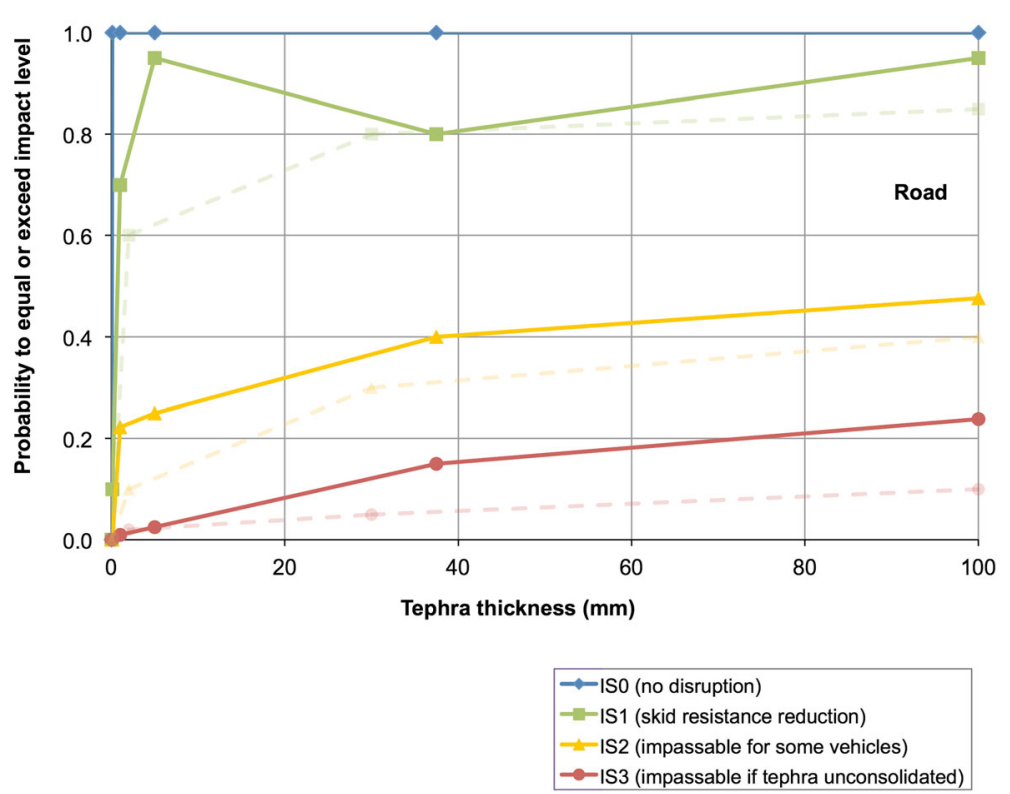

Fig. 4 Fragility functions for road transportation (solid lines) updated from Wilson et al. 2017 (dashed lines). These have been updated with empirical data from skid resistance and road marking coverage laboratory experiments 
have limitations - see section 3.4) but is somewhat supported by semi-quantitative field observations. A decreasing fragility function breaks one of the core guidelines established by Wilson et al. 2017, which states that "functions should not decrease as the HIM value increases". However, this guideline was established for damage rather than functional loss, and for when there is limited data to base vulnerability estimates on (i.e. not accounting for detailed empirical studies).

Airports can be closed due to ash in nearby airspace, without any ground accumulation of ash (Guffanti et al. 2009). Indeed, the International Civil Aviation Organisation (ICAO) advise that "aircraft should avoid volcanic ash encounters" (p.1-1), although "the operator is responsible for the safety of its operations" (p.2-1) and is required to complete a risk assessment as part of its safety management system, and have satisfied the relevant national (or supra-national) CAA before initiating operations into airspace forecast to be, or at airports known to be, contaminated with volcanic ash (ICAO 2012). Aircraft will likely become grounded due to a reduced runway friction coefficient when ash deposits exceed $1 \mathrm{~mm}$ (ICAO 2001, Wilson et al. 2017). Furthermore, severe deterioration in local visibility can result when engine exhausts from aircraft taxiing, landing and taking off disturb ash on the runway (ICAO 2001).

We assess functionality loss of airfields by applying the key findings from skid resistance and road marking coverage experiments for airfield concrete surfaces covered by ash (Fig. 3). It is important to consider such impact types, as aircraft operation may be possible when airborne ash concentrations are below aviation authority, and airline and airport guideline values. Although vehicle operation on airfields by ground staff could occur, even when aircraft are grounded, we focus on aircraft operations for the fragility function chart (Fig. 5). These fragility functions estimate the temporal duration of airport function assuming that the surrounding airspace is open and prior to any clean-up. Some functionality loss of the airport surface is possible between 0.1 and $1.0 \mathrm{~mm}$ due to markings becoming covered and reduced skid resistance (Blake et al. 2016, 2017a) before the airport is likely closed if ash accumulates to $>1 \mathrm{~mm}$ thickness. We display the temporal component for airport closure graphically as separate ISs (Fig. 5) as such information may be beneficial for end-users of fragility functions.

\section{New ash-settling rate fragility functions}

Figure 6 shows IS thresholds for visibility with ashsettling rate adopted as the HIM. Forecasts for visibility disruption are particularly useful for areas where there is minimal ash accumulation on the ground (i.e. during initial ashfall events or subsequent events following thorough clean-up), as well as for maritime transportation and where surfaces are wet due to any resuspension of ash into the atmosphere being minimised by water. Many of the thresholds established in Fig. 6 , and depicted in new fragility function charts in Fig. 7, are particularly influenced by decisions made by local transportation authorities and we stress that our established thresholds are preliminary and open for improvement. Best judgement by the authors is used to determine some thresholds. For example, IS1 starts at $10 \mathrm{~g} \mathrm{~m}^{-2} \mathrm{~h}^{-1}$ for road, but at $20 \mathrm{~g} \mathrm{~m}^{-2} \mathrm{~h}^{-1}$ for rail, due to the relative resilience of rail to airborne ash, which results from more automated controls and fixed paths of travel (Blake et al. 2017b). IS thresholds may require adaptation to be compatible in other areas, especially where infrastructure types and associated technology differ. Thresholds are established for visibility only and do not consider other potential disruption caused by airborne volcanic ash such as ingestion into engines or the abrasion of windscreens.

A literature search revealed no quantitative or semiquantitative data for visual ranges at specified ashsettling rates following previous eruptions worldwide. Figure 7 shows fragility functions for the ash-settling rate HIM, based entirely on empirical laboratory studies and comparisons to research for fog, to indicate expected impact on visibility and vehicles at near-ground level. Further extensive laboratory testing, in addition to syn- and post-eruption field surveys, will help to refine probabilities. Studies of ash remobilisation and resuspension will likely improve our understanding of potential links between ash thickness and settling rate.

We emphasise that our studies were carried out in the context of transportation infrastructure found in New Zealand (e.g. ash characteristics and pavement properties found in the country) and that fragility functions may vary in different parts of the world. However, we suspect the trends will remain similar.

\section{Multiple hazard intensity metrics}

Figure 8 presents the results of comparative analysis of six additional HIMs identified during laboratory experimentation as having effects on surface skid resistance and road marking coverage.

This was achieved by using best judgement considering recent laboratory experiments to apply simple rank values to each HIM. The core HIM of ash thickness was used with the values of alternative HIMs dependent on relative importance to one another.

It is clear from Fig. 8 that as ash increases in thickness on the ground, the effect of different HIMs on surface transportation functionality changes. For example, particle size and colour play an important role below $\sim 1.0 \mathrm{~mm}$ thickness due to the effect of fine-grained and 

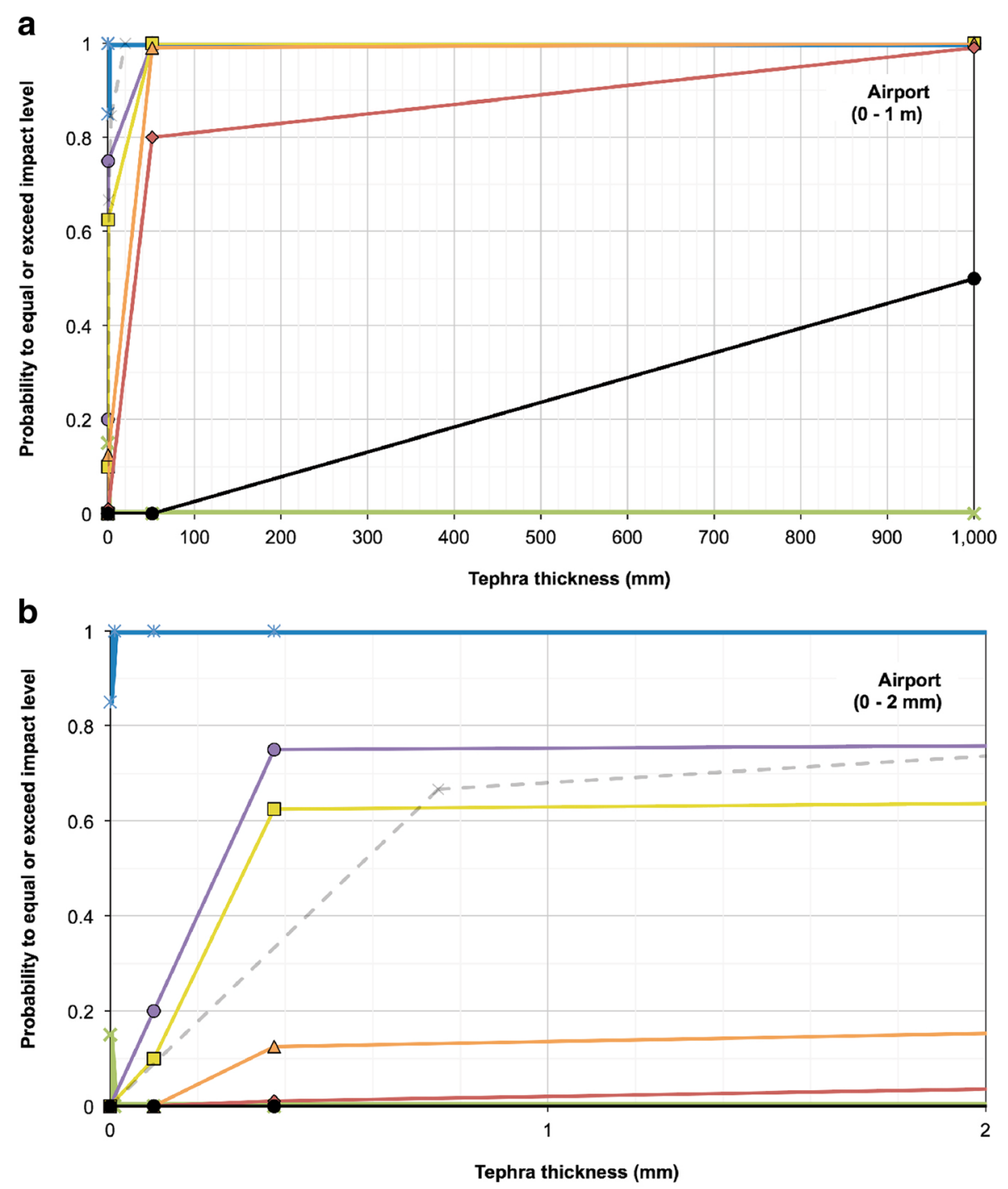

IS-1 (increased function due to ash threat, e.g. runway extension)
- IS0 (no disruption)
- -IS1 (skid resistance reduction, marking coverage)
$\square-$ IS2 (temporary closures)
$\rightarrow$ IS4 (closures for hours to days)
$\rightarrow-$ IS5 (permanes for 1 week to several weeks)

Fig. 5 New fragility functions for airport transportation surfaces developed from post-eruption and laboratory experimental data. New fragility functions for airport transportation surfaces developed from post-eruption and laboratory experimental data ( $\mathbf{a}$ at $0-1 \mathrm{~m}$ tephra thickness, $\mathbf{b}$ a magnified version of the same results at 0-2 mm tephra thickness). The previous function for "airport closure" developed by Wilson et al. (2017) is shown by the grey dashed lines. Note that most points have been corrected to fit with the rules and principles for fragility function development, as outlined by Wilson et al. (2017), and some using best judgement by the authors

light-coloured ash on road marking coverage, but less of a role when ash thickness exceeds $\sim 1.0 \mathrm{~mm}$. However, the wetness of ash is important compared to other HIMs when ash thicknesses are $>10 \mathrm{~mm}$ because it influences how readily ash binds together, in turn affecting how easily vehicles can drive through thicker deposits.

Arguably even more relevant for fragility functions is the relative importance of additional HIMs for visibility impairment (Fig. 9). Unlike ash thickness, there is no evidence to suggest that the importance of different HIMs relative to one another changes as settling rate changes. However, results from Blake (2016) indicate that, as for thickness, the effect of additional HIMs has a lesser effect on functionality loss for greater ash-settling rates. This is likely due to the more dominant effect of there simply being more ash particles in the atmosphere. The HIM characteristics responsible for greater disruption are largely the same as for ash thickness (Fig. 8), 


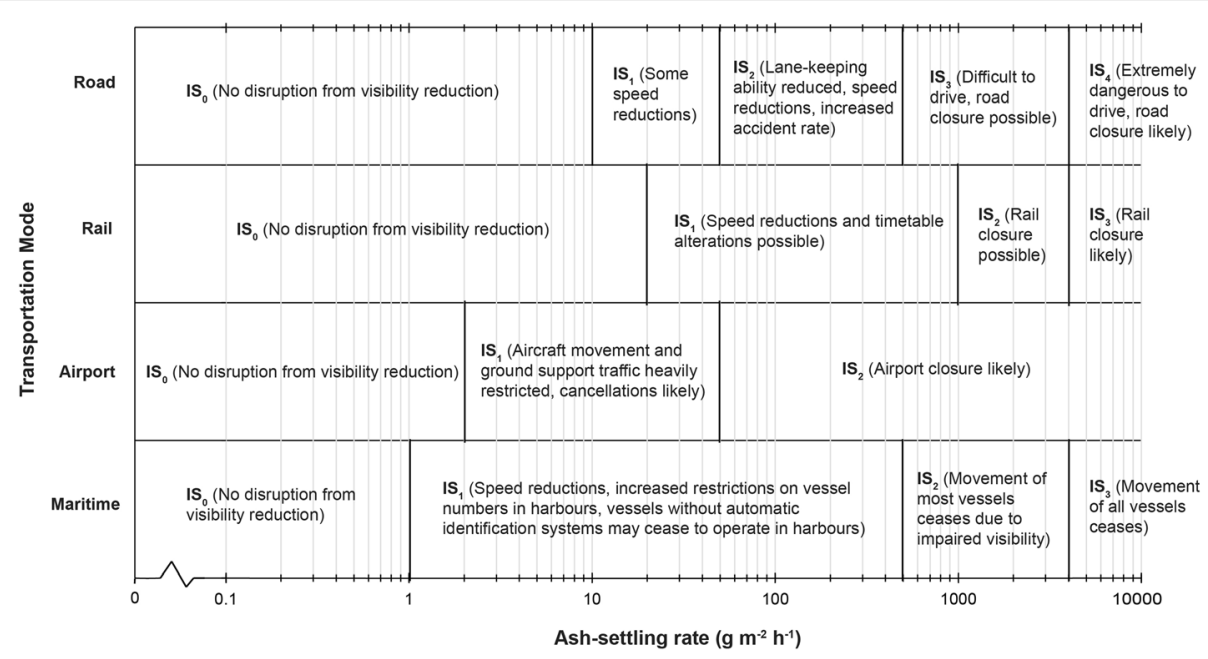

Fig. 6 Impact states for expected visibility-related disruption to surface transportation as a function of ash-settling rate. These are determined from quantitative laboratory experiments by Blake (2016), and comparisons to visual range and driver behaviour in fog. Thresholds have been derived in the context of transportation in New Zealand
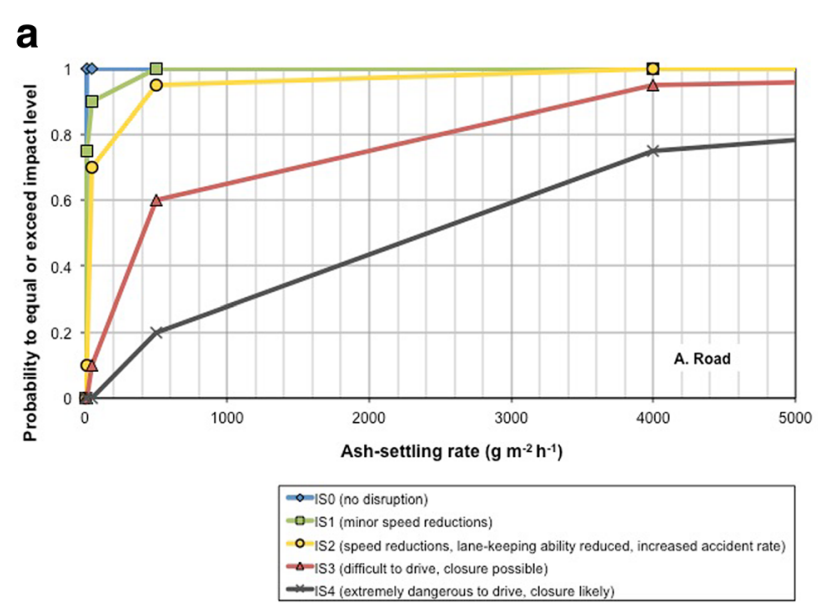

C

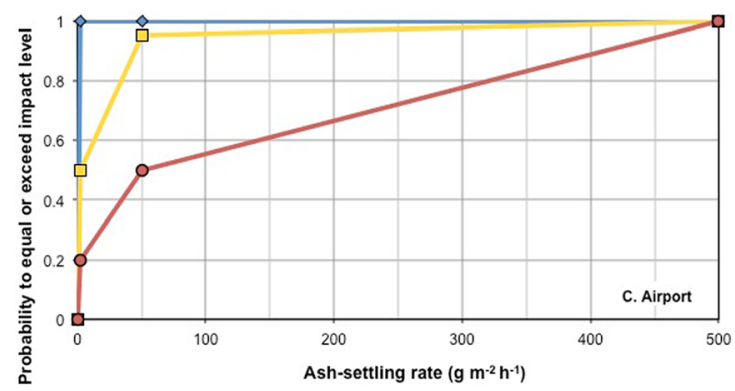

$\rightarrow-1 \mathrm{SO}$ (no disruption)

- IS1 (aircraft and ground support vehicle restrictions)
- O-IS2 (closure likely) b

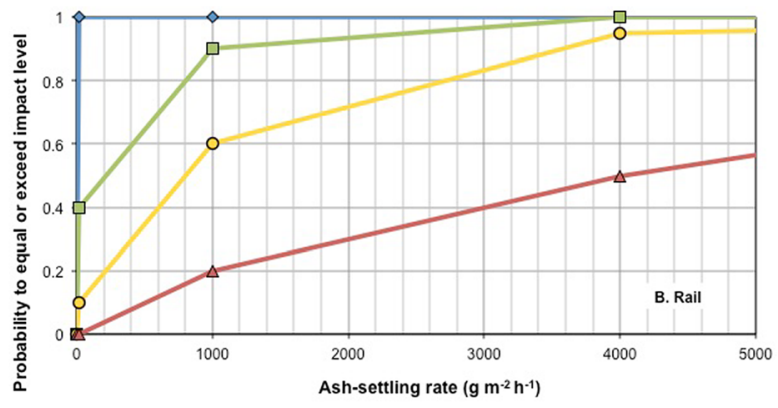

$\rightarrow$ - ISO (no disruption) - IS1 (speed reductions, timetable alterations) - IS2 (closure possible)

$\rightarrow-$ IS3 (closure likely)

\section{d}

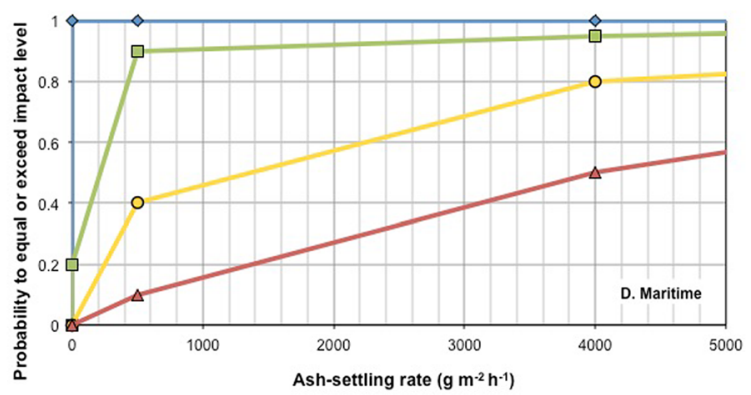

$\rightarrow$ ISO (no disruption)

-IS1 (speed reductions, some restrictions on vessel movement in harbours) - isz (mostrassolmovement ceases)

Fig. 7 Fragility function charts for visibility impacts on a road, $\mathbf{b}$ rail, $\mathbf{c}$ airports, and $\mathbf{d}$ maritime transportation, with ash-settling rate as the HIM 

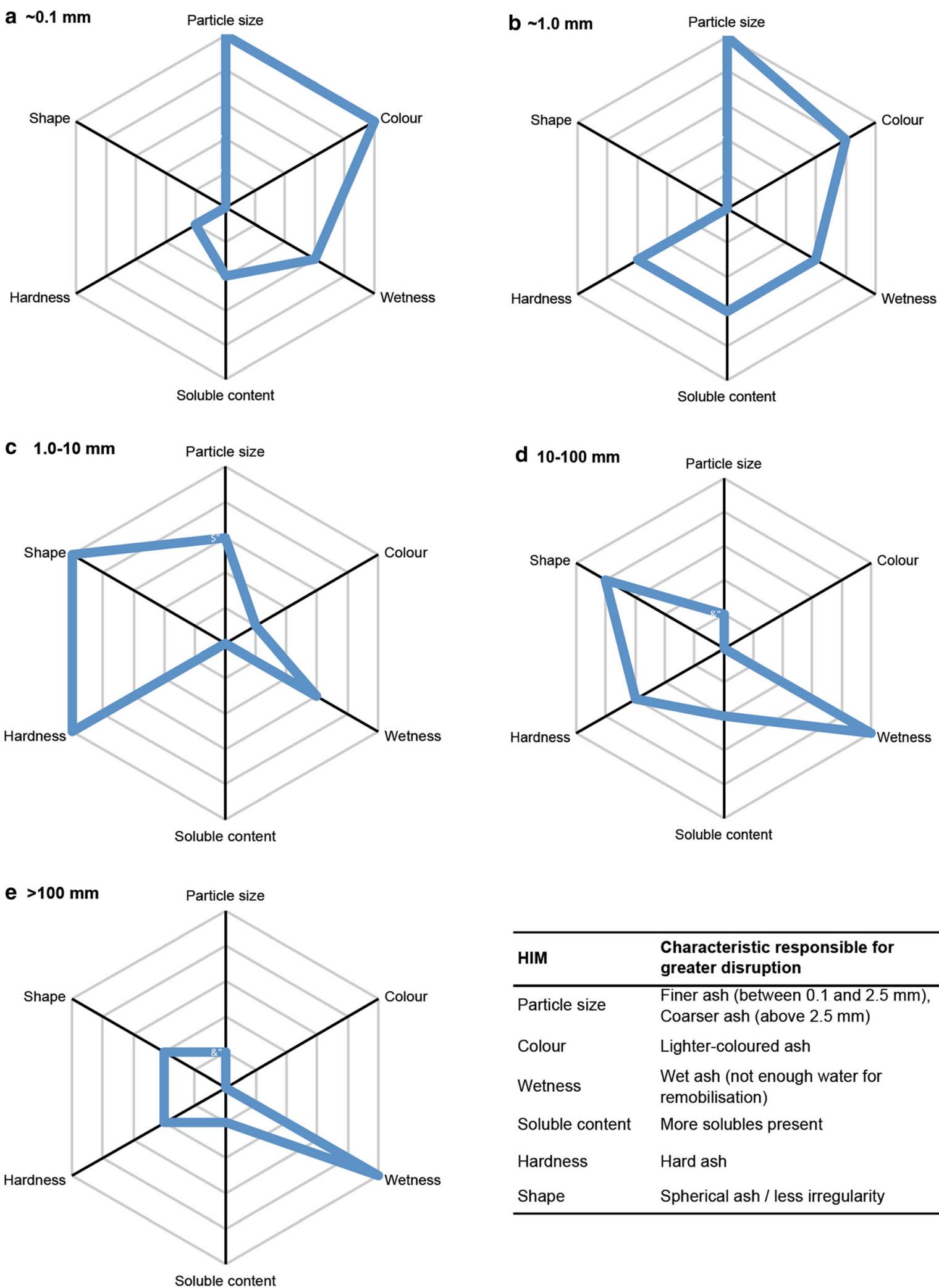

\begin{tabular}{|c|c|}
\hline HIM & $\begin{array}{l}\text { Characteristic responsible for } \\
\text { greater disruption }\end{array}$ \\
\hline Particle size & $\begin{array}{l}\text { Finer ash (between } 0.1 \text { and } 2.5 \mathrm{~mm} \text { ), } \\
\text { Coarser ash (above } 2.5 \mathrm{~mm} \text { ) }\end{array}$ \\
\hline Colour & Lighter-coloured ash \\
\hline Wetness & $\begin{array}{l}\text { Wet ash (not enough water for } \\
\text { remobilisation) }\end{array}$ \\
\hline Soluble content & More solubles present \\
\hline Hardness & Hard ash \\
\hline Shape & Spherical ash / less irregularity \\
\hline
\end{tabular}

Fig. 8 Relative importance of additional HIMs at key ash thickness intervals (a-e). The charts consider the impact types of skid resistance reduction and road marking coverage in combination. Values towards the outside of the radar charts indicate lower rank values / greater importance for surface transportation disruption. The key shows the particular characteristic of each HIM responsible for greater disruption 


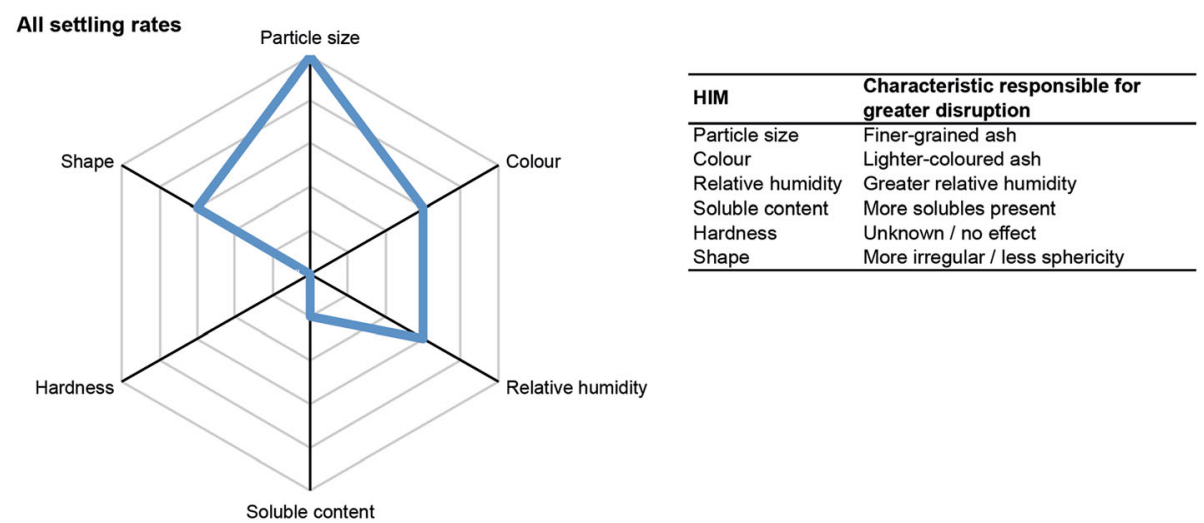

Fig. 9 Relative importance of additional HIMs for the impact type of visibility impairment. The key shows the characteristic of each HIM responsible for greater disruption to surface transportation. Note that there is no evidence at present to suggest that the importance of HIMs change relative to one another as ash-settling rate changes

with the exception of ash particle shape; irregularshaped ash particles may lead to greater disruption when airborne due to more light reflectance and subsequently lower visual range, whereas spherical-shaped ash particles can lead to greater disruption when on paved surfaces as a result of lower skid resistance. Particle size is clearly a crucial ash characteristic to consider when assessing surface transportation disruption, especially for $<10 \mathrm{~mm}$ thicknesses.

Further repeated laboratory experiments to investigate the effect of each ash characteristic on every surface transportation impact type, along with detailed post- eruption field sampling and analysis, and subsequent computational probabilistic modelling will assist to fill this gap in knowledge. In the meantime, and in the absence of extensive datasets, it is difficult to evaluate the precise quantitative effect of alternative HIMs (i.e. those other than ash thickness and settling rate) on surface transportation disruption from volcanic ash and perform meaningful statistical analysis. However, we suggest that the importance of multiple HIMs can be accounted for by considering 'error boundaries' that illustrate uncertainty around existing functions for ash thickness and settling rate (Fig. 10) (although other

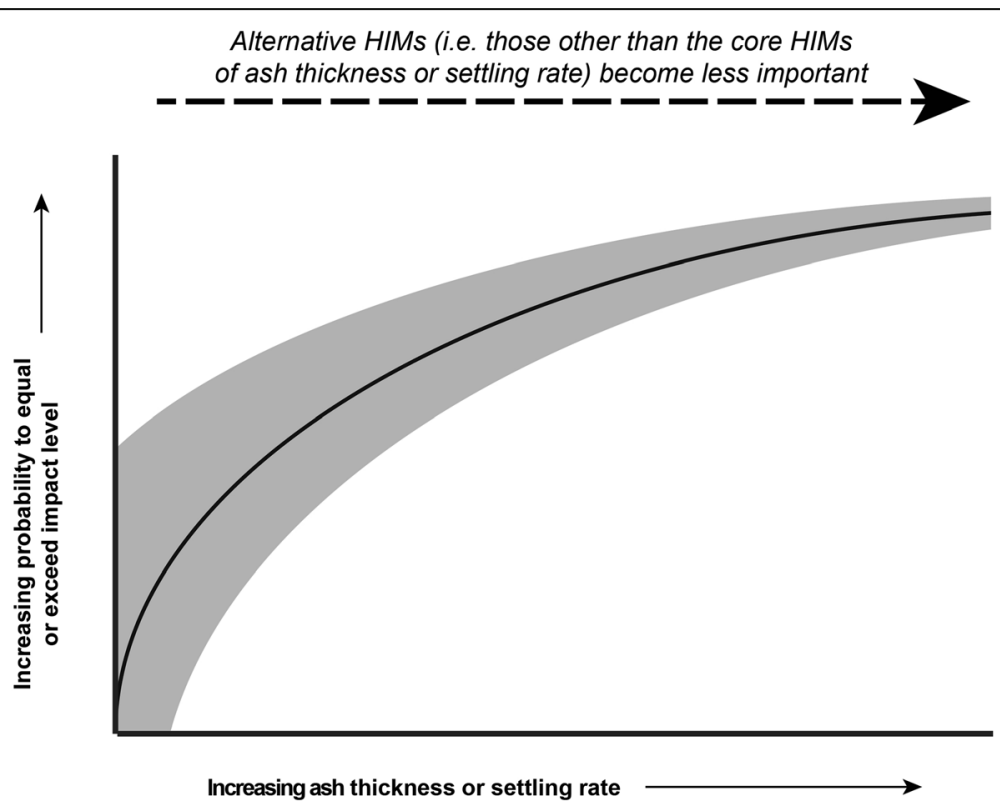

Fig. 10 Example of fragility curve to conceptually demonstrate the relative importance of 'alternative HIMs' to 'core HIMs'. The importance of 'alternative HIMs' is depicted by the light shading. Used in conjunction with the radar charts in Fig. 9 (which were derived from laboratory experimentation), probabilities (shown on the $y$-axis) can be better estimated using such fragility functions. However, we note that the 'errors extents' displayed here are arbitrary at this stage 
uncertainties also exist). The conceptual diagram (Fig. 10) shows that with thicker ash or greater ashsettling rates, alternative HIMs (e.g. particle size, colour, shape) become less important with it being more beneficial to solely consider the core HIMs of ash thickness or ash-settling rate when forecasting impact levels.

\section{Conclusion}

We conclude that ash thickness and settling rate are the critical HIMs for the assessment of surface transportation functionality during volcanic ashfall events. However, due to current difficulties in quantifying the impact that ash thickness has on visibility impairment (the key impact type relatable to ash-settling rate and relevant for all modes of surface transportation), the two HIMs are not directly comparable and should be considered separately. For the ash thickness HIM, we identify the potential for fluctuating intensities of road transportation disruption as thickness increases, a feature that has not been identified in the past from empirical studies and is a product of experimental data obtained from targeted laboratory testing for specific impact types. We highlight that disruption can occur at an order of magnitude less than previously indicated (i.e. for thicknesses of $\sim 0.1 \mathrm{~mm}$ rather than $1.0 \mathrm{~mm}$ ) due to the potential for surface marking coverage; fragility functions for road and airports have been updated accordingly. Although highly subjective, preliminary fragility functions for visibility with ash-settling rate adopted as the HIM have been established using empirical data alone and by making comparisons to impacts previously identified in fog.

Our analysis of alternative HIMs (i.e. other than the critical HIMs of ash thickness and settling rate) and their effect on volcanic ash fragility function development for surface transportation leads to several key findings:

- Although ash thickness and settling rate should be treated as core HIMs for the assessment of surface transportation disruption, alternative HIMs should not be overlooked.

- Ash particle size is identified as the next most important HIM for functionality loss, especially when airborne concentrations and accumulations of ash on the ground are relatively small.

- For different ash thicknesses, the relative importance of alternative HIMs may be different. However, for different ash-settling rates there is no evidence to suggest that alternative HIMs change in their relative importance to one another.

- As ash thickness and ash-settling rates increase, alternative HIMs have less of an influence on surface transportation functionality loss. This confirms that it is indeed appropriate to consider ash thickness and settling rate as core HIMs for surface transportation impact assessments.

- Without extensive datasets, it is difficult to accurately model the effect of alternative HIMs on disruption. However, we suggest that they could be incorporated into fragility functions by implementing 'error boundaries', alongside descriptors for the specific ash characteristic features responsible for increased probabilities of impact states being reached or exceeded.

Our findings support the need to provide forecasts and actively monitor a range of ash characteristics in areas that may be affected by volcanic ashfall, especially the thickness of deposits on the ground and ash-settling rate, but also other ash properties including particle size distributions, colour, and shape. This should be prioritised where there are abundant exposed surface transportation networks and populations: potential disruption can occur with $\sim 0.1 \mathrm{~mm}$ ash thickness on the ground, depending on the ash characteristics present. Additional (particularly quantitative) datasets derived from new eruptions and laboratory tests will assist with the advancement of volcanic ash fragility functions for surface transportation, thus allowing further improvements in risk assessments and contingency planning in volcanically active regions.

\section{Additional file}

Additional file 1: Summary of key findings from recent laboratory experiments to investigate impacts of volcanic ash on surface transportation. (DOCX $19 \mathrm{~kb})$

\section{Abbreviations}

CAA: Civil aviation authority; HIM: Hazard intensity metric; ICAO: International civil aviation organisation; IS: Impact state; MNZ: Maritime New Zealand; PDC: Pyroclastic density current; TRB: Transport research board; UNISDR: United nations international strategy for disaster reduction

\begin{abstract}
Acknowledgements
We acknowledge all the technical and financial support received to conduct the extensive laboratory experimentation on surface transportation impacts from volcanic ash. Although the results were not directly covered in this paper (they are covered in separate publications), many of the key findings would not have been possible without these initial studies. Particular thanks are expressed to the New Zealand Earthquake Commission (EQC),

Determining Volcanic Risk in Auckland (DEVORA) project, Natural Hazards Research Platform (NHRP), University of Canterbury Mason Trust, and GNS Science Core Programme funding scheme for their recent support to the authors. Also, the financial support from the University of Canterbury Department of Geological Sciences is greatly appreciated, which allowed the purchase of key laboratory equipment. Daniel Blake would like to thank his additional PhD co-supervisors, Jan Lindsay (The University of Auckland) and Jim Cole (University of Canterbury), for their edits, guidance and advice throughout this study. This paper was improved by the comments of two anonymous reviewers.
\end{abstract}

\section{Authors' contributions}

DMB planned, coordinated and led all the laboratory experimental work for volcanic ash surface transportation impacts mentioned in this paper. He also 
planned the research and wrote this paper including the development of methodologies and illustrations. NID and TMW assisted with method development and provided suggestions for improvements throughout the process and conducted thorough edits of the manuscript. GW contributed by providing the initial methodologies for fragility function production and a final edit of the manuscript. All authors have read, reviewed and approved the final version.

\section{Competing interests}

The authors declare that they have no competing interests.

\section{Publisher's Note}

Springer Nature remains neutral with regard to jurisdictional claims in published maps and institutional affiliations.

\section{Author details}

${ }^{1}$ Department of Geological Sciences, University of Canterbury, Private Bag, Christchurch 4800, New Zealand. ${ }^{2}$ GNS Science, PO Box 30-368, Lower Hutt 5040, New Zealand. ${ }^{3}$ Present address: Office of Emergency Management, Havelock Street, West Perth, WA, Australia.

\section{Received: 22 June 2016 Accepted: 30 August 2017}

Published online: 03 October 2017

\section{References}

Auckland Airport (2008) Newsroom: Fog at Auckland Airport and Category IIIB. 19 November 2008, Auckland Airport. http://www.aucklandairport.co.nz/ / media/3FF843AAFCBB4C23B941EAA7406EAB7B.ashx?sc_database=web. Accessed 19 Mar 2016.

Auckland Council. Harbourmaster's Office operation of vessels during periods of restricted visibility: navigation safety operating requirements. Auckland, New Zealand: Auckland Council; 2014

Barnard S. The vulnerability of New Zealand lifelines infrastructure to ashfall. Christchurch, New Zealand: PhD Thesis, Hazard and Disaster Management, University of Canterbury; 2009.

Binkowski FS, Roselle SJ, Mebest MR, Eder BK. In: Chock DP, Carmichael GR, editors. Modeling atmospheric particulate matter in an air quality modelling system using a modal method, Atmospheric modelling. The IMA volumes in mathematics and its applications 130; 2002.

Blake DM, Wilson G, Stewart C, Craig HM, Hayes JL, Jenkins SF, Wilson TM, Horwell CJ, Andreastuti S, Daniswara R, Ferdiwijaya D, Leonard GS, Hendrasto M, Cronin S (2015) The 2014 eruption of Kelud volcano, Indonesia: impacts on infrastructure, utilities, agriculture and health. GNS Science Report 2015/15 139p.

Blake DM. Impacts of volcanic ash on surface transportation networks: considerations for Auckland City, New Zealand. PhD Thesis, Department of Geological Sciences, University of Canterbury, Christchurch, New Zealand. 2016.

Blake DM, Wilson TW, Gomez C. Road marking coverage by volcanic ash: an experimental approach. Environ Earth Sci. 2016;75(20):1-12.

Blake DM, Wilson TM, Cole JW, Deligne NI, Lindsay JM. Impact of volcanic ash on road and airfield surface skid resistance. Sustainability. 2017a;9(8):1389.

Blake DM, Deligne NI, Wilson TM, Lindsay JM, Woods R. Investigating the consequences of urban volcanism using a scenario approach II: insights into transportation network damage and functionality. J Volcanology Geotherm Res. 2017b;340:92-116.

Blong R. A new damage index. Nat Hazards. 2003;30:1-23.

Blong RJ. Volcanic hazards: a sourcebook on the effects of eruptions. Sydney: Academic Press Inc; 1984.

Board HR. National Cooperative Highway Research Program Synthesis of highway practice 14: skid resistance. Washington D.C: Highway Research Board, National Academy of Sciences; 1972.

CAA. Low Visibility Operations at Auckland Airport. Vector: Pointing to Safer Aviation, Issue 4. Civil Aviation Authority of New Zealand. 2007. https://www. caa.govt.nz/Publications/Nector/Nector_2007_Issue4_JulAug.pdf. Accessed 11 Sept 2017.

Choi E, DesRoches R, Nielson B. Seismic fragility of typical bridges in moderate seismic zones. Eng Struct. 2004;26:187-99.

Craig H, Wilson T, Stewart C, Outes V, Villarosa G, Baxter P. Impacts to agriculture and critical infrastructure in Argentina after ashfall from the 2011 eruption of the Cordón Caulle volcanic complex: an assessment of published damage and function thresholds. J Appl Volcanol. 2016a;5(7):31.
Craig H, Wilson T, Stewart C, Villarosa G, Outes V, Cronin S, Jenkins S. Agricultural impact assessment and management after three widespread tephra falls in Patagonia, South America. Nat Hazards. 2016b;82(2):1167-229.

Deligne NI, Fitzgerald R, Blake DM, Davies AJ, Hayes JL, Stewart C, Wilson G, Wilson TM, Carneiro R, Kennedy B, Muspratt S, Woods R. Investigating the consequences of urban volcanism using a scenario approach I: development and application of a hypothetical eruption in the Auckland Volcanic Field, New Zealand. J Volcanol Geotherm Res. 2017;336:192-208.

Deligne NI, Blake DM, Davies AJ, Grace ES, Hayes J, Potter S, Stewart C, Wilson G, Wilson TM (2015) Economics of Resilient Infrastructure Auckland Volcanic Field scenario. ERI Research Report 2015/03 151p.

Dunn MG. Operation of gas turbine engines in an environment contaminated with volcanic ash. J Turbomach. 2012;134(5):18.

Guffanti M, Mayberry GC, Casadevall TJ, Wunderman R. Volcanic hazards to airports. Nat Hazards. 2009;51:287-302.

Hayes JL, Wilson TM, Magill C. Tephra fall clean-up in urban environments. J Volcanol Geotherm Res. 2015;304:359-77.

Horwell CJ, Baxter PJ, Hillman SE, Damby DE, Delmelle P, Donaldson K, Dunster C, Calkins JA, Fubini B, Hoskuldsson A, Kelly FJ, Larsen G, Le Blond JS, Livi KJT, Mendis B, Murphy F, Sweeney S, Tetley TD, Thordarson T, Tomatis M. Respiratory health hazard assessment of ash from the 2010 eruption of Eyjafjallajökull volcano, Iceland: a summary of initial findings from a multicentre laboratory study. Durham, UK: IVHHN and Durham University; 2010.

Hyslop N. Impaired visibility: the air pollution people see. Atmos Environ. 2009;43(1):182-95.

ICAO (2001) Manual on volcanic ash, radioactive material and toxic chemical clouds. http://www3.alpa.org/portals/alpa/volcanicash/12_ Doc9691ManuallCAOVolAshRadioactiveMaterial.pdf. Accessed 16 Jun 2016.

ICAO (2012) Flight safety and volcanic ash: risk management of flight operations with known or forecast volcanic ash contamination. International Civil Aviation Organisation. http://www.icao.int/publications/Documents/9974_en. pdf. Accessed 16 Jun 2016.

Jenkins S, Komorowski J-C, Baxter P, Spence R, Picquout A, Lavigne F. The Merapi 2010 eruption: an interdisciplinary impact assessment methodology for studying pyroclastic density current dynamics. J Volcanol Geotherm Res. 2013;261:316-29.

Jenkins SF, Spence RJS, Fonseca JFBD, Solidum RU, Wilson TM. Volcanic risk assessment: quantifying physical vulnerability in the built environment. J Volcanol Geotherm Res. 2014a;276:105-20.

Jenkins SF, Wilson TM, Magill CR, Miller V, Stewart C (2014b) Volcanic ash fall hazard and risk: technical background paper for the UN-ISDR Global Assessment Report on Disaster Risk Reduction 2015. http://www. preventionweb.net/english/hyogo/gar/2015/en/home/documents.html. Accessed 19 Apr 2016.

Johnston DM. Physical and social impacts of past and future volcanic eruptions in New Zealand. Palmerston North, New Zealand: PhD Thesis, Earth Science, Massey University; 1997.

Johnston DM, Daly M. Auckland erupts!! New Zealand Sci Monthly. 1997;8(10):6-7.

Jolly GE, Keys HJR, Procter JN, Deligne NI. Overview of the co-ordinated riskbased approach to science and management response and recovery for the 2012 eruptions of Tongariro volcano, New Zealand. J Volcanol Geotherm Res. 2014;286:184-207.

Leonard GS, Stewart C, Wilson TM, Procter JN, Scott BJ, Keys HJ, Jolly GE, Wardman JB, Cronin SJ, McBride SK. Integrating multidisciplinary science, modelling and impact data into evolving, syn-event volcanic hazard mapping and communication: a case study from the 2012 Tongariro eruption crisis, New Zealand. J Volcanol Geotherm Res. 2014;286:208-32.

MNZ (2015) Maritime Rules Part 22: Collision Prevention. Maritime New Zealand, Wellington, New Zealand. http://www.maritimenz.govt.nz/rules/part-22/. Accessed 19 Mar 2016

Nairn IA (2002) The effects of volcanic ash fall (tephra) on road and airport surfaces. GNS Science Report 2002/13 32p.

Nanayakkara KIU, Dias WPS. Fragility curves for structures under tsunami loading. Nat Hazards. 2016:80(1):471-86.

Porter K, Kennedy R, Bachman R. Creating fragility functions for performancebased earthquake engineering. Earthquake Spectra. 2007;23(2):471-89.

Porter KA, Farokhnia K, Cho IH, Rossetto T, loannou I, Grant D, Jaiswal K, Wald D, D'Ayala D, Meslem A, So E, Kiremidjian AS, Noh H (2012) Global vulnerability estimation methods for the Global Earthquake Model. Proceedings for the 15th World Conference on Earthquake Engineering, 24-28 September 2012, 4504 
Reese S, Ramsay D (2010) RiskScape: flood fragility methodology. NIWA Technical Report WLG2010-45 $42 \mathrm{p}$.

Rossetto T, D'Ayala D, loannou I, Meslem A. Evaluation of existing fragility curves. In: Pitilakis K, Crowley H, Kaynia AM (Eds). SYNER-G: typology definition and fragility functions for physical elements at seismic risk. Dordrecht: Springer; 2014.

Rossetto T, loannou I, Grant DN. Exisiting empirical vulnerability and fragility functions: compendium and guide for selection. GEM technical report 2013X. Pavia, Italy: GEM Foundation; 2013.

Singhal A, Kiremidjian AS. Method for probabilistic evaluation of seismic structural damage. J Struct Eng. 1996;122:1459-67.

Stewart C, Horwell C, Plumlee G, Cronin S, Delmelle P, Baxter P, Calkins J, Damby D, Mormon S, Oppenheimer C. Protocol for analysis of volcanic ash samples for assessment of hazards from leachable elements. IAVCEI, IVHHN, Cities on Volcanoes Commission, USGS, GNS Science. 2013. http://www.ivhhn.org/ images/pdf/volcanic_ash_leachate_protocols.pdf.

Tarbotton C, Dall'Osso F, Dominey-Howes D, Goff J. The use of empirical vulnerability functions to assess the response of buildings to tsunami impact: comparative review and summary of best practice. Earth Sci Rev. 2015;142:120-34.

TRB. Transportation options for megacities in the developing world: a working paper, transport research board. In: NRC (1996), editor. Meeting the challenges of megacities in the developing world: a collection of working papers. Washington DC, United States: National Research Council, National Academy Press; 1996.

UNISDR (2009) UNISDR terminology on disaster risk reduction. United Nations International Strategy for Disaster Reduction, Geneva, Switzerland. http://www. unisdr.org/files/7817_UNISDRTerminologyEnglish.pdf. Accessed 21 Apr 2016.

Wardman J, Sword-Daniels V , Stewart C, Wilson T (2012) Impact assessment of the May 2010 eruption of Pacaya volcano, Guatemala. GNS Science Report 2012/09 90p.

Wilson G. Vulnerability of critical infrastructure to volcanic hazards. Christchurch, New Zealand: PhD Thesis in Hazards and Disaster Management, Department of Geological Sciences, University of Canterbury; 2015.

Wilson G, Wilson TM, Deligne NI, Blake DM, Cole JW. Framework for developing volcanic fragility functions for critical infrastructure. J Applied Volcanol. 2017.

Wilson G, Wilson TM, Deligne NI, Cole JW. Volcanic hazard impacts to critical infrastructure: a review. J Volcanol Geotherm Res. 2014;286:148-82.

Wilson TM, Stewart C, Sword-Daniels V, Leonard GS, Johnston DM, Cole JW, Wardman J, Wilson G, Barnard ST. Volcanic ash impacts to critical infrastructure. Phys Chem Earth. 2012;45-46:5-23.

Wilson TW, Stewart C, Cole JW, Dewar DJ, Johnston DM, Cronin SJ (2011) The 1991 eruption of Volcán Hudson, Chile: impacts on agriculture and rural communities and long-term recovery. GNS Science Report 2009/66 99 p.

\section{Submit your manuscript to a SpringerOpen ${ }^{\circ}$ journal and benefit from:}

- Convenient online submission

- Rigorous peer review

- Open access: articles freely available online

- High visibility within the field

- Retaining the copyright to your article

Submit your next manuscript at $\gg$ springeropen.com 